\title{
Accuracy of mandibular measurements of sexual dimorphism using stabilizer equipment
}

\section{Thais Torralbo LOPEZ(a) \\ Edgard MICHEL-CROSATO(a) Eduardo de Novaes BENEDICTO(a) Luiz Airton Saquedra de PAIVA(b) Diogo Cesar Borges SILVA ${ }^{(c)}$ Maria Gabriela Haye BIAZEVIC(a)}

(a) Universidade de São Paulo - USP, School of Dentistry, Department of Community Dentistry, São Paulo, SP, Brazil.

(b) Institute of Teaching and Research in Forensic Sciences, Guarulhos, SP, Brazil.

(c) Instituto de Pesquisas Tecnológicas - IPT, Microprecision Dimensional Metrology and Metrotomography Laboratory, São Paulo, SP, Brazil.

Declaration of Interests: The authors certify that they have no commercial or associative interest that represents a conflict of interest in connection with the manuscript.

Corresponding Author: Maria Gabriela Haye Biazevic E-mail: biazevic@usp.br

DOI: 10.1590/1807-3107BOR-2017.vol31.0001

Submitted: Sep 30, 2015

Accepted for publication: Sep 14, 2016

Last revision: Sep 29, 2016
Abstract: The objective of this investigation was to compare the accuracy of mandibular measurements using a stabilizer (MS) with gold standard computed tomography (GS) images. Sixty mandibles were studied. Werth TomoScope HV Compact ${ }^{\circledR}$ was used to obtain CT images (GS), and the MS was also used. Analysis of the CT scans was performed using the VG Studio Max software ${ }^{\circledR}$ (Volume Graphics GmbH, Heidelberg, Germany), and MS was used after the proper positioning of the mandible. Descriptive and paired $t$ test measures were used, and a ROC curve was calculated, as well as sensibility and specificity. MedCalc and STATA $13.0 ®$ were used ( $95 \%$ level of significance). Bicondylar breadth, bicoronoid breadth and minimum ramus breadth reached the highest concordance correlation coefficients at 0.99 (0.99-1.00), 0.99 (0.99-1.00) and 1.00 (0.99-1.00), respectively. Comparing observers with GS, the lowest accuracy was noted for the maximum mandibular length $[0.59(0.45-0.69)$, 0.64 (0.51-0.74)], the breadth of the right (0.14 (0.04-0.23), $0.14(0.004-0.24))$ and left mandibular body [0.14 (0.03-0.24), $0.16(0.05-0.26)]$, and the right [0.58 (0.45-0.69), $0.63(0.51-0.73)$ and left $(0.59$ (0.45-0.70), 0.59 (0.46-0.69)] mandibular angle. Various measurements exhibited good sensibility for males using MS: maximum mandibular length (78.12), bicondylar breadth (78.12), left mandibular notch breadth (84.37), and the left height of the mandibular body at the mental foramen (75.00). High specificity in discriminating females was observed for the left maximal ramus height (85.19), mandibular length (85.71), bicoronoid breadth (96.43), right height of the mandibular body at the mental foramen (82.19), bimental breadth (78.57), breadth right (92.86) and left (96.43) mandibular body, minimum ramus breadth (89.29), and left mandibular angle (85.71). MS was able to discriminate sexual dimorphism.

Keywords: Mandible; Tomography Scanners, X-Ray Computed; Anthropology; Sex Determination Analysis.

\section{Introduction}

The field of anthropology offers important parameters to understand human variability that can be useful for forensic purposes and the study of evolutionary processes. ${ }^{1}$ The skeleton offers countless characteristics that indicate sexual dimorphism. In this regard, skulls and mandibles have been described as highly useful both in historical and modern collections. 
In this context, various studies ${ }^{2,34,5}$ have demonstrated that several anatomic landmarks of the skull and mandible can be used and that some of these landmarks typically present increased precision in identifying an individual compared with other. ${ }^{3}$ Furthermore, the mandible is one of the most preserved bones in hominid and hominoid fossil records, ${ }^{6}$ making it relevant to anthropological studies.

Several techniques have been cited, and most of them describe qualitative parameters to perform the evaluations. As these parameters are subjective, more accurate results are typically achieved by experts. Furthermore, most international investigations use qualitative parameters to perform the measurements; thus, there is a need for methods that are reproducible (quantitative) in measuring mandibular characteristics.

Some authors consider that due to recent migrations, genetic flow and difficulties in determining skeleton ancestry, morphological analysis is limited. $2,3,4,5,7,8$ On the other hand, the metric method is gaining increasing importance as technical reports or case discussion on tribunals make it necessary to statistically present data to prove a specific point of view. Additionally, a less subjective argumentation highlights the reliability of the data. ${ }^{9,10,11,12,13}$ However, the quantification of the structures used in the metric method is not yet well understood.

Considering the lack of standardization of mandible measurements, we built a piece of equipment (mandibular stabilizer, MS) that standardizes the position of the mandible and allows us to perform quantitative measurements. Therefore, the objective of this investigation was to compare the accuracy of mandibular measurements using the mandibular stabilizer (MS) with gold standard computed tomography (GS) images of Brazilian mandibles.

\section{Methodology}

Sixty mandibles from the Institute of Teaching and Research in Forensic Sciences of Guarulhos were studied. After proper training and achieving acceptable concordance levels (kappa test), two calibrated observers obtained 13 measurements of the mandible. Calibration was performed using mandible samples other than those used in the study.
In the first method, the mandibles were analyzed using 3D images. To perform these measurements, we used a Multisensor Coordinate Measurement Machine that has X-ray Tomography as one of its sensors, the Werth TomoScope HV Compact ${ }^{\circledR}$ (Werth Messtechnik GmbH, Gieben, Germany) (Figure 1). This equipment is located at the Laboratory of Micromanufacturing at the Institute for Technological Research (IPT) in São Paulo, Brazil. The TomoScope can reach levels of precision highly superior to those of a typical cone beam $\mathrm{CT}$, and a resolution of $5 \mu \mathrm{m}$ can be achieved. Analysis of the CT scans was performed using the VG Studio Max software ${ }^{\circledR}$ (Volume Graphics $\mathrm{GmbH}$, Heidelberg, Germany). The mandibular measurements using the TomoScope were considered the gold standard (GS).

In the second method, a mandibular stabilizer was used (Figure 2). The equipment was developed with the aim of making measurements easier with more precision and to create measurement standards. The equipment has a base, a fixation and positioning table, and a measurement table. The patent registration was requested from the National Institute of Industrial Property in Brazil (INPI), BR 102013 003270-0. The mandible measurements are described in Table 1 and presented in Figure 3.

The reproducibility and accuracy were presented using descriptive statistics showing the sample size, mean and standard deviation. Additionally, the coefficient of variation, single and average intraclass correlation, concordance correlation coefficient $(95 \% \mathrm{CI})$, and Pearson and bias correction factors were presented. To verify the sexual dimorphism, descriptive and paired $t$ test measures were used, and a ROC curve was fabricated. The sensibility and specificity were also calculated. MedCalc ${ }^{\circledR}$ (MedCalc Software bvba, Ostend, Belgium) and STATA 13.0® (StataCorp LP, College Station- TX, USA) were used at a $95 \%$ of level of significance.

This investigation is in accordance with the international and national parameters of ethics for the investigation of human beings; the investigation protocol was submitted and approved by the Ethics Committee of the University of São Paulo's School of Dentistry (FOUSP), process number 350.960. 

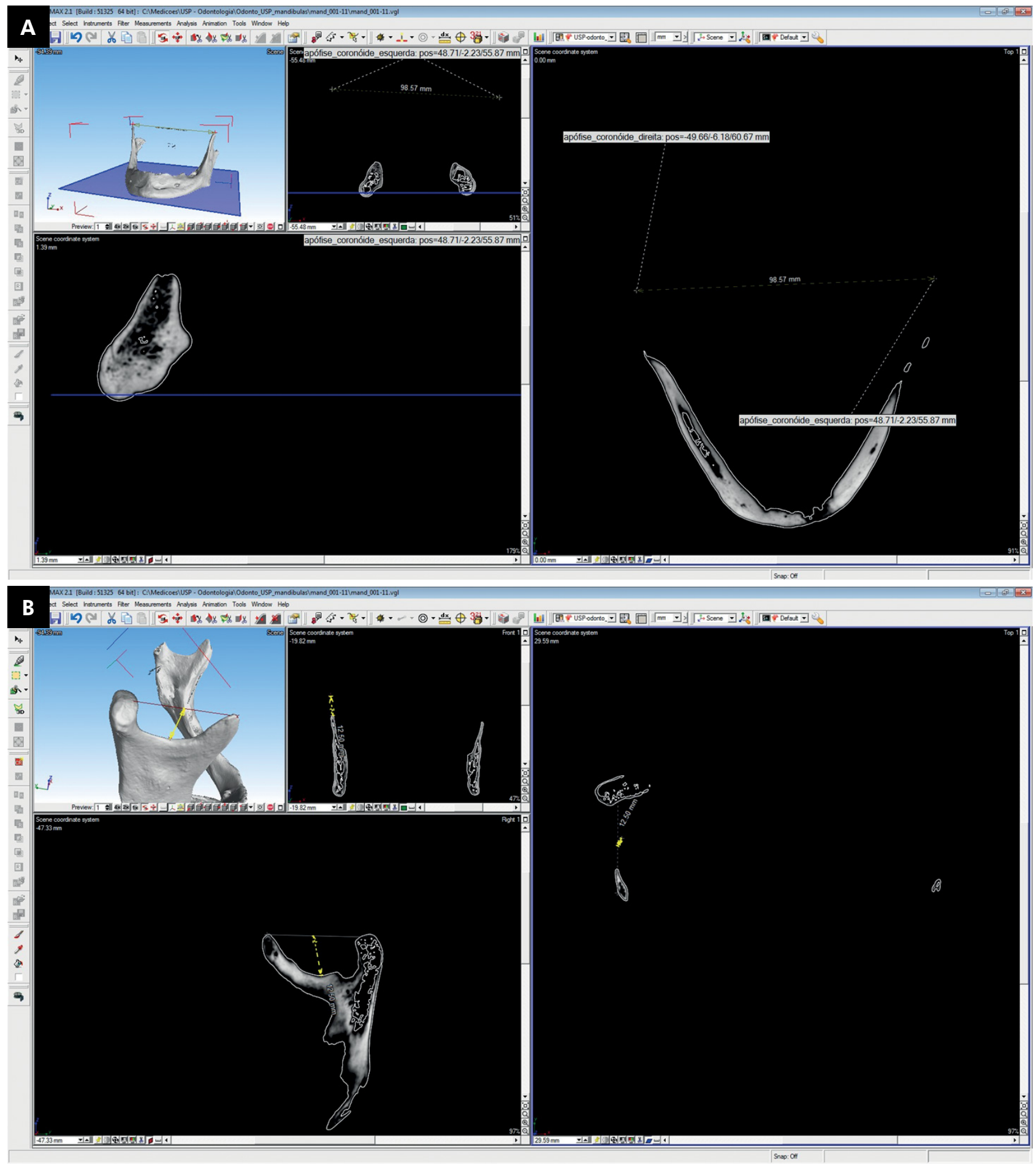

Figure 1. CT mandible images (gold standard). la: bicoronoid breadth; 1b: mandibular notch depth.

\section{Results}

Table 2 presents the descriptive data of sex and age estimation of the samples. Tables 3 and 4 present the reproducibility and accuracy results of the measurements. Bicondylar breadth, bicoronoid breadth and minimum ramus breadth reached the highest concordance correlation coefficients, with 
values of 0.99 (0.99- 1.00), 0.99 (0.99-1.00) and 1.00 (0.99-1.00) (Table 3), respectively. On the other hand, mandibular notch breadth and mandibular notch depth presented lower results in this regard (0.85 $(0.73-0.92)$ and $0.80(0.70-0.87)$, respectively) (Table 3$)$.
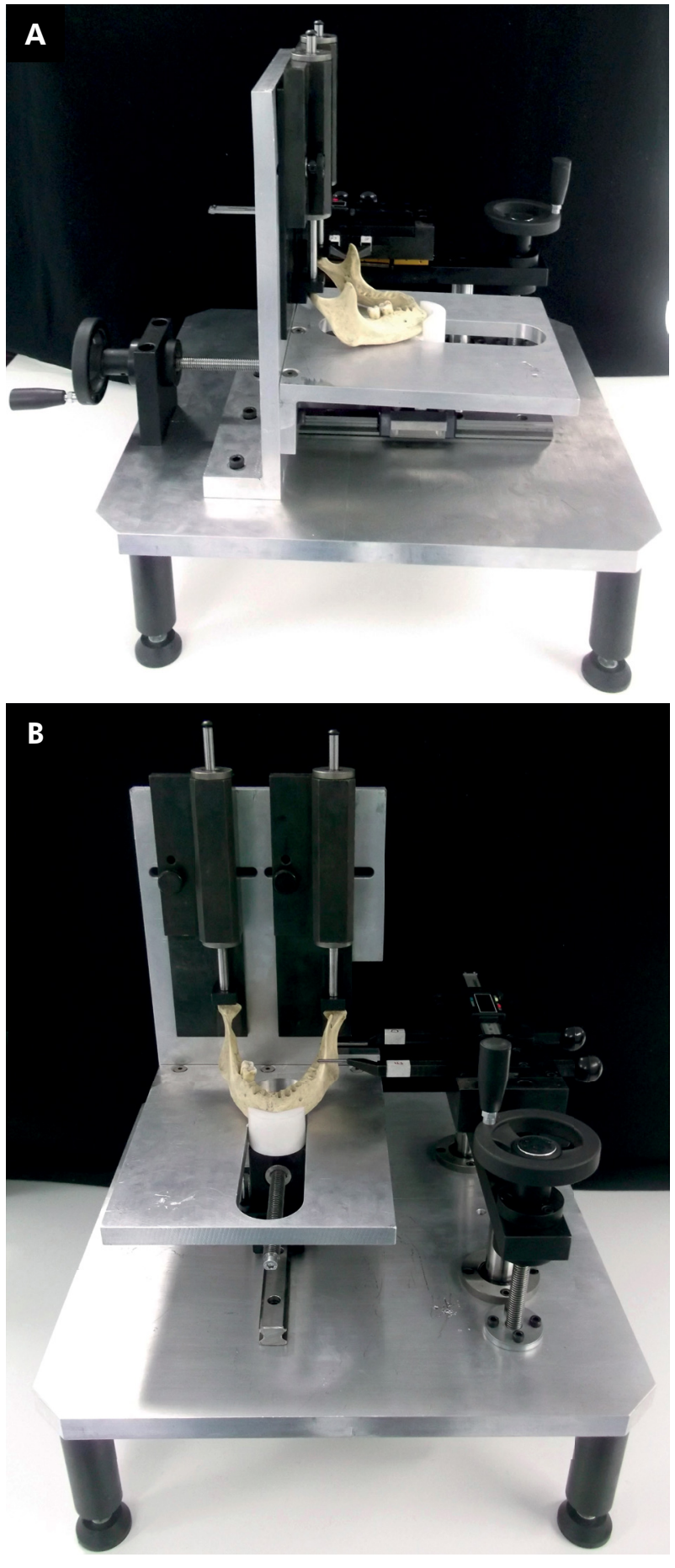

Figure 2. Mandible stabilizer.
Comparing observer 1 and 2's measurements with the gold standard, the lowest accuracy measurements were found for maximum mandibular length [0.59 (0.45-0.69), 0.64 (0.51-0.74)], breadth of the right $[0.14(0.04 \mathrm{v} 0.23), 0.14(0.004-0.24)]$ and left [0.14 (0.03-0.24), 0.16 (0.05-0.26)] mandibular body, and right $[0.58(0.45-0.69), 0.63(0.51-0.73)$ and left (0.59 (0.45-0.70), $0.59(0.46-0.69)]$ mandibular angle (data not shown in tables).

Tables 4 and 5 present the variables and the sexual dimorphism. In Table 4, the results are presented as the means of the values among male and female mandibles. All mean measurements were higher in male mandibles, and most of them correctly showed differences between the sexes using both the gold standard (GS) and the mandible stabilizer (MS). Some values did not differ between males and females when the mandible stabilizer (MS) was used: mandibular length $(\mathrm{p}=0.146)$, breadth of the right and left $(\mathrm{p}=0.135$ and $p=0.432$, respectively) mandibular body, and the right and left ( $p=0.215$ and $p=0.301$, respectively) mandibular angle. The only measurement using the GS that did not show differences between the sexes was the right and left $(\mathrm{p}=0.128$ and $\mathrm{p}=0.215$, respectively) mandibular angle.

Table 5 shows the ROC curve results. Some measurements exhibited good sensibility for male mandibles using the MS as follows: the maximum mandibular length (78.12), the bicondylar breadth (78.12), the left mandibular notch breadth (84.37), and the left height of the mandibular body at the mental foramen (75.00). The GS performed better for the right maximum ramus height (93.75) in the male sample. High specificity in discriminating female mandibles was observed for the left maximus ramus height (85.19), the mandibular length (85.71), the bicoronoid breadth (96.43), the right height of the mandibular body at the mental foramen (82.19), the bimental breadth (78.57), the breadth of the right (92.86) and left (96.43) mandibular body, the minimum ramus breadth (89.29), the left mandibular angle (85.71), variables using MS and the bigonial width (89.29), the bicoronoid breadth (96.43), the breadth of the right (85.71) and left (85.19) mandibular notch, the right height of the mandibular body at the mental foramen (78.57), 
Table 1. Mandible measurements.

\begin{tabular}{|c|c|c|}
\hline Variable number & Measurement & Definition \\
\hline Varl & Maximum mandibular length & $\begin{array}{l}\text { Distance from the anterior midline point on the chin (pogonion) to a center point of the } \\
\text { bigonion line. }\end{array}$ \\
\hline Var2 & Bigonial width & Direct distance between the right and left gonion. \\
\hline Var3 & Maximum ramus height* & Direct distance from the highest point on the mandibular condyle to the gonion. \\
\hline Var4 & Mandibular length (projection) & $\begin{array}{l}\text { Distance from the anterior midline point on the chin (pogonion) to the perpendicular line } \\
\text { tangent to the posterior point of the left condyle. }\end{array}$ \\
\hline Var5 & Bicondylar breadth & Direct distance between the most lateral points on the two condyles (condylion laterale). \\
\hline Var6 & Bicoronoid breadth & Direct distance between the points at the tip of the two coronoid processes (coronion). \\
\hline Var7* & Mandibular notch breadth* & Direct distance from the condylion superior point to the coronion. \\
\hline Var8* & Height of mandibular body* & $\begin{array}{l}\text { Direct distance from the alveolar process to the inferior border of the mandible } \\
\text { perpendicular to the base at the level of the mental foramen. }\end{array}$ \\
\hline Var9* & Bimental breadth & $\begin{array}{l}\text { Direct distance between the most inferior point on the margin of the mandibular mental } \\
\text { foramen (mentale). }\end{array}$ \\
\hline Var10* & Breadth of mandibular body* & $\begin{array}{l}\text { Maximum breadth measured in the region of the mental foramen perpendicular to the } \\
\text { long axis of the mandibular body. }\end{array}$ \\
\hline $\operatorname{Var} 11^{*}$ & Minimum ramus breadth & Minimum breadth of the mandibular ramus measured perpendicular to the height of the ramus. \\
\hline Var12* & Mandibular angle* & Angle formed by the inferior border of the corpus and the posterior border of the ramus. \\
\hline Var13* & Mandibular notch depth* & $\begin{array}{l}\text { Distance from the deepest part of the mandibular notch, to a center point of the } \\
\text { condylion superior - (coronion) line. }\end{array}$ \\
\hline
\end{tabular}

*Bilateral measurements (left and right).

the bimental breadth (82.14), the right breadth of the mandibular body (78.57), the minimum ramus breadth (85.71), and the right mandibular angle (92.86) using GS (Table 5).

\section{Discussion}

The objective of comparing the accuracy of the MS with GS demonstrated that the MS can discriminate sex in mandibles. High observer concordance was noted in some anatomical landmarks, and these landmarks should be preferred to discriminate sex.

The sample had more male than female mandibles, and $40 \%$ of the sample had an age estimation in the range of 60 to 79 years. It must be highlighted that age estimation is prone to variability. In addition, less precision is achieved in older samples. ${ }^{14}$

In general, a high level of agreement between the observers was observed, indicating that the MS method is reproducible. One recommendation should be the need to be trained to perform the measurements. Thus, training with theoretical discussions and practical activities are necessary to achieve high levels of reproducibility when performing comparisons with a gold standard. This topic should be considered in the area of forensics given that sex determinations must be performed in numerous settings.

Bicondylar breadth, bicoronoid breadth and minimum ramus breadth reached the highest concordance coefficients; this was an expected result because these measurements are based on easy-to-find anatomical landmarks. On the other hand, mandibular notch breadth and depth reached lower concordance rates because these anatomical landmarks require more expert knowledge and training to be established.

As mentioned in the results section, the lowest accuracy measures were observed for the maximum mandibular length, the breadth of the mandibular body and the mandibular angle. The maximum mandibular length was the distance from the pogonion (the most anterior point of the mentonian prominence) and the tangent perpendicular of the posterior part of the condyle. Therefore, this localization can be exposed to variations among different observers because it corresponds to a projection. When using the VG StudioMax program to perform the GS measurements, the program 
automatically generated this perpendicular line, so the GS was considerably more precise than the observers using the MS.

As expected, the breadth of the mandibular body also has limitations during measurements due to the presence of teeth and tori. Again, given that the mandibular angle is the angle formed by the lower border of the mandibular body and the posterior border of the ramus, it was expected that the software would achieve more precise measurements than MS.

Differences were observed between GS and MS. MS has demonstrated good accuracy to discriminate the sex of mandibles, allowing a standardization of the measurements performed by experts and in training professionals. This feature may be very useful for forensic anthropology settings.

Some measurements have displayed better results than others in discriminating sex. Williams and Rogers ${ }^{3}$ evaluated the accuracy of some morphological traits among skulls and mandibles in a skeletal collection in Tennessee, U.S.A., and they found that the goniac angle exhibited high precision and low accuracy. Another study performed in Brazil found that the bigonial width and mandibular ramus height obtained good results in discriminating sex, ${ }^{15}$ our study observed similar results for discriminating sex with the maximum ramus height compared with a Korean study. ${ }^{16}$ Furthermore, studies have highlighted that the shape of the mandible can offer a better contribution than the size for sex determination in Gorilla, Pongo and H. s. syndactylus and to a lesser extent in modern humans. ${ }^{1,6}$

Some mandibular measurements did not accurately discriminate sex with MS: the mandibular length and the breadth of the mandibular body.

Table 2. Descriptive data of the sample (mandibles).

\begin{tabular}{lcc}
\hline Variable & $n$ & $\%$ \\
\hline Sex & & \\
$\quad$ Male & 32 & 53.34 \\
$\quad$ Female & 28 & 46.66 \\
Age (in years) & & \\
$17-39$ & 10 & 16.67 \\
$40-59$ & 16 & 26.66 \\
$60-79$ & 24 & 40.00 \\
$80+$ & 10 & 16.67 \\
\hline
\end{tabular}

Some authors also found similar results, especially when comparing different ethnic groups. ${ }^{17}$ Additionally, the mandibular angle measured using both methods did not show values sufficient to discriminate male and female mandibles probably due to the difficulties in establishing anatomical reference marks. A Korean study ${ }^{16}$ revealed sex differences $(p<0.032)$. The literature indicates

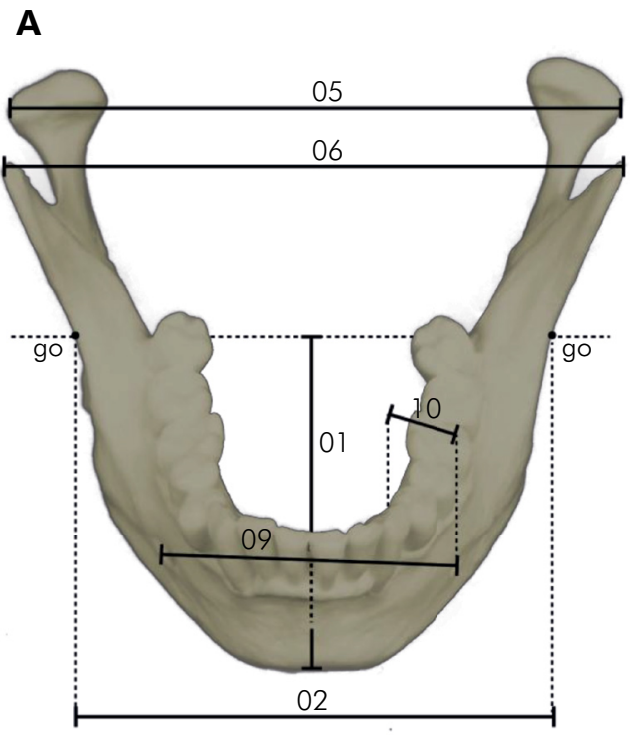

B

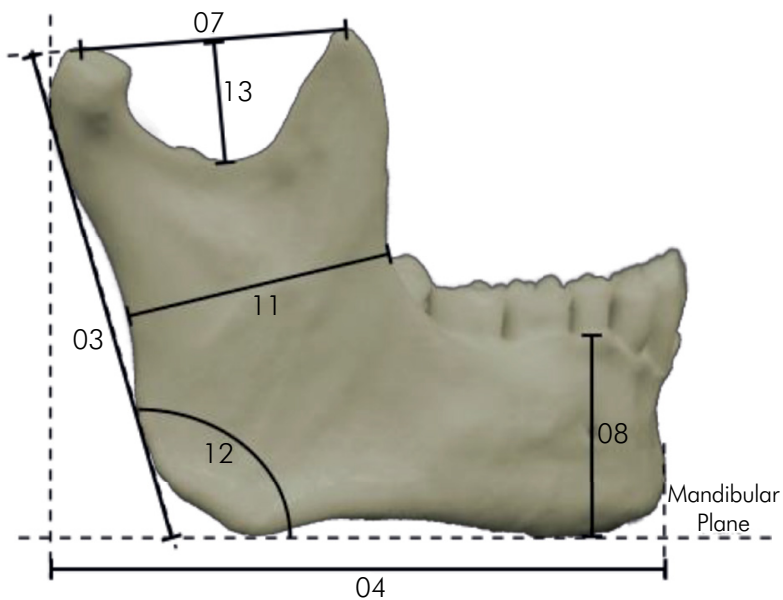

Figure 3. Mandible measurements. 1. maximum mandibular length; 2. bigonial width; 3. maximum ramus height, right and left; 4. mandibular length (projection); 5. bicondylar breadth; 6. bicoronoid breadth; 7. mandibular notch breadth, right and left; 8 . height of the mandibular body at the mental foramen, right and left; 9. bimental breadth; 10. breadth of the mandibular body, right and left; 11. minimum ramus breadth; 12. mandibular angle, right and left; 13. mandibular notch depth, right and left. 
Table 3. Reproducibility of the measurements per variable.

\begin{tabular}{|c|c|c|}
\hline Variable & Reproducibilit & iurements \\
\hline & Diff $a, C^{b},\left(I C\right.$ Single ${ }^{c}$ and average $\left.{ }^{d}\right)$ & $0.70,1,55,(0.93$ and 0.97$)$ \\
\hline 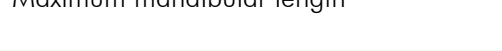 & CCCe $(95 \% \mathrm{Cl})$, Pearson $\rho^{\dagger}, \mathrm{BCF}^{g}$ & $0.92(0.89-0.96), 0.93,0.99$ \\
\hline Rinnnigl width & Diff $^{a}, \mathrm{CV}^{\mathrm{b}},\left(\mathrm{IC}\right.$ Single ${ }^{\mathrm{d}}$ and average $\left.{ }^{\mathrm{e}}\right)$ & $1.42,1.94,(0.95$ and 0.98$)$ \\
\hline 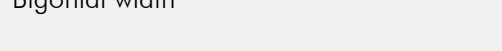 & CCC $(95 \% \mathrm{Cl})$, Pearson $\rho, \mathrm{BCF}$ & $0.93(0.89-0.96), 0.95-0,96$ \\
\hline & Diffa, $C V^{b},\left(I C\right.$ Single ${ }^{d}$ and average $\left.{ }^{e}\right)$ & $0.80,1.79,(0.98-0.99)$ \\
\hline - & CCC $(95 \% \mathrm{Cl})$, Pearson $\rho, \mathrm{BCF}$ & $0.98(0.96-0.99), 0.98,0.99$ \\
\hline & Diffa, ${ }^{a} V^{b},\left(I C\right.$ Single ${ }^{d}$ and average $\left.{ }^{e}\right)$ & $0.58,2.14,(0.97$ and 0.98$)$ \\
\hline 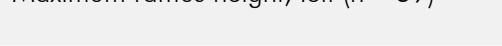 & CCC $(95 \% \mathrm{Cl})$, Pearson $\rho, \mathrm{BCF}$ & $0.96(0.94-0.98), 0.97,0.99$ \\
\hline & Diff $^{a}, \mathrm{CV}^{b},\left(\mathrm{IC} \mathrm{Single}^{\mathrm{d}}\right.$ and average $\left.{ }^{\mathrm{e}}\right)$ & $0.28,1.44,(0.96-0.98)$ \\
\hline (v) & CCC $(95 \% \mathrm{Cl})$, Pearson $\rho, \mathrm{BCF}$ & $0.96(0.94-0.98) .0 .96,0.99$ \\
\hline & Diffa, $\mathrm{CV}^{\mathrm{b}}$, (IC Single ${ }^{\mathrm{d}}$ and average $\left.{ }^{\mathrm{e}}\right)$ & $0.21,0.41,(0.99-1.00)$ \\
\hline ( & CCC $(95 \% \mathrm{Cl})$, Pearson $\rho, \mathrm{BCF}$ & $0.99(0.99-1.00), 1.00,1.00$ \\
\hline Risomenid henodth & Diffa, $\mathrm{CV}^{\mathrm{b}},\left(\mathrm{IC} \mathrm{Single}^{\mathrm{d}}\right.$ and average $\left.{ }^{\mathrm{e}}\right)$ & $0.28,0.57,(0.9-1.00)$ \\
\hline 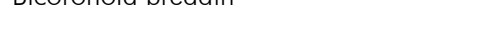 & CCC $(95 \% \mathrm{Cl})$, Pearson $\rho$, BCF & $0.99(0.99-1.00), 0.99,1.00$ \\
\hline & Diffa, ${ }^{a} V^{b},\left(I C\right.$ Single ${ }^{d}$ and average $\left.{ }^{e}\right)$ & $0.29,2.81,(0.93-0.96)$ \\
\hline 1 & $\mathrm{CCC}(95 \% \mathrm{Cl})$, Pearson $\rho, \mathrm{BCF}$ & $0.93(0.88-0.95), 0.93,0.99$ \\
\hline odth left $(n-50)$ & Diff $^{\circ}, C^{b}$, (IC Single ${ }^{c}$ and average $\left.{ }^{d}\right)$ & $0.95,4.54,(0.88-0.93)$ \\
\hline 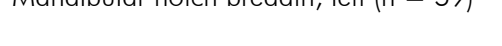 & $\mathrm{CCC}^{\mathrm{e}}(95 \% \mathrm{Cl})$, Pearson $\rho^{\dagger}, \mathrm{BCF}^{g}$ & $0.85(0.73-0.92), 0.89,0.95$ \\
\hline Height of the mandibular body at the & Diffa, $C V^{b},\left(I C\right.$ Single ${ }^{d}$ and average $\left.{ }^{e}\right)$ & $0.18,3.58,(0.98-0.99)$ \\
\hline mental foramen, right & CCC $(95 \% \mathrm{Cl})$, Pearson $\rho$, BCF & $0.98(0.96-0.99), 0.98,1.00$ \\
\hline Height of the mandibular body at the & Diff ${ }^{a}, C^{b},\left(I C\right.$ Single ${ }^{d}$ and average $\left.{ }^{e}\right)$ & $0.10,3.22,(0.98-0.99)$ \\
\hline mental foramen, left & CCC $(95 \% \mathrm{Cl})$, Pearson $\rho, \mathrm{BCF}$ & $0.98(0.97-0.99), 0.99,1.00$ \\
\hline & Diffa, ${ }^{a} V^{b},\left(I C\right.$ Single ${ }^{d}$ and average $\left.{ }^{e}\right)$ & $0.20,1.30,(0.96-0.98)$ \\
\hline 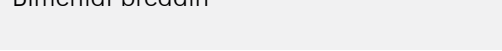 & CCC $(95 \% \mathrm{Cl})$, Pearson $\rho, \mathrm{BCF}$ & $0.96(0.94-0.98), 0.96,1.00$ \\
\hline Breadth of the mandibular hodv riabt & Diff $^{a}, C^{b},\left(I C\right.$ Single ${ }^{d}$ and average $\left.{ }^{e}\right)$ & $0.12,4.16,(0.95-0.98)$ \\
\hline De & CCC $(95 \% \mathrm{Cl})$, Pearson $\rho, \mathrm{BCF}$ & $0.96(0.93-0.97), 0.95,0.99$ \\
\hline Broadth of the mandibular hedv left & Diff $^{\circ}, \mathrm{CV}^{\mathrm{b}}$, (IC Single ${ }^{\mathrm{d}}$ and average $\left.{ }^{\mathrm{e}}\right)$ & $0.09,4.58,(0.96-0.98)$ \\
\hline 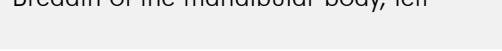 & CCC $(95 \% \mathrm{Cl})$, Pearson $\rho, \mathrm{BCF}$ & $0.96(0.92-0.97), 0.96,1.00$ \\
\hline Minimum ramus hreadth /n & Diffa, $C V^{b},\left(I C\right.$ Single ${ }^{d}$ and average $\left.{ }^{e}\right)$ & $0.07,0.78,(1.00-1.00)$ \\
\hline - & CCC $(95 \% \mathrm{Cl})$, Pearson $\rho, \mathrm{BCF}$ & $1.00(0.99-1.00), 1.00,1.00$ \\
\hline Mandibular angle riaht & Diff $^{\circ}, \mathrm{CV}^{\mathrm{b}}$, (IC Single ${ }^{\mathrm{d}}$ and average $\left.{ }^{e}\right)$ & $0.70,1.56,(0.93-0.97)$ \\
\hline 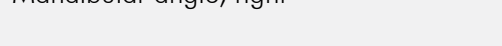 & CCC $(95 \% \mathrm{Cl})$, Pearson $\rho$, BCF & $0.93(0.89-0.95), 0.93,0.97$ \\
\hline Mandibular analo loft & Diff $^{a}, C^{b}$, (IC Single ${ }^{c}$ and average $\left.{ }^{d}\right)$ & $0.73,1.64,(0.93-0.97)$ \\
\hline 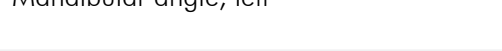 & CCCe $(95 \% \mathrm{Cl})$, Pearson $\rho^{\dagger}, \mathrm{BCF}^{\mathrm{g}}$ & $0.92(0.88-0.95), 0.93,0.99$ \\
\hline oular notch donth riabt $(n-50)$ & Diff $^{a}, \mathrm{CV}^{b}$, (IC Single ${ }^{c}$ and average $\left.{ }^{d}\right)$ & $0.70,7.14,(0.85-0.91)$ \\
\hline जिa & $\mathrm{CCC}^{\mathrm{e}}(95 \% \mathrm{Cl})$, Pearson $\rho^{f}, \mathrm{BCF}^{g}$ & $0.80(0.70-0.87), 0.86,0.94$ \\
\hline Mandihular notch denth left $(n=56)$ & Diff $a, C V^{b},\left(I C\right.$ Single ${ }^{c}$ and average $\left.{ }^{d}\right)$ & $0.47,3.84,(0.96-0.98)$ \\
\hline & $\mathrm{CCC}^{\mathrm{e}}(95 \% \mathrm{Cl})$, Pearson $\rho^{f}, \mathrm{BCF}^{g}$ & $0.94(0.90-0.96), 0.97,0.98$ \\
\hline
\end{tabular}

${ }^{a}$ difference; ${ }^{b}$ coefficient of variation (\%); Intraclass correlation: ${ }^{c}$ single and daverage; concordance correlation coefficient $(95 \% \mathrm{Cl})$; 'Pearson's $\rho$ (precision); ${ }^{9}$ Bias correction factor $C_{b}$. 
Table 4. Descriptive statistics of the measurements using the mandible statibilizer (MS) and the tomographic measurements (GS, golden standard) for each sex.

\begin{tabular}{|c|c|c|c|c|c|c|c|c|c|c|c|c|c|}
\hline \multirow{3}{*}{ Variable } & \multicolumn{13}{|c|}{ Descriptive measurements } \\
\hline & \multicolumn{7}{|c|}{ Male } & \multicolumn{3}{|c|}{ Female } & \multirow[b]{2}{*}{ Max } & \multirow[b]{2}{*}{ Diff } & \multirow[b]{2}{*}{$p$} \\
\hline & Cat & bs & Mean & SD & Min & Mar & Obs & Mean & $\mathrm{cm}$ & Min & & & \\
\hline \multirow{2}{*}{$\begin{array}{l}\text { Maximum mandibular } \\
\text { length }\end{array}$} & MS & 32 & 104.06 & 6.20 & 89.79 & 116.76 & 28 & 97.96 & 6.81 & 82.70 & 109.47 & 6.10 & 0.001 \\
\hline & GS & 32 & 107.86 & 6.62 & 92.96 & 122.83 & 28 & 103.40 & 6.12 & 89.70 & 115.77 & 4.46 & 0.001 \\
\hline \multirow{2}{*}{ Bigonial width } & MS & 32 & 92.76 & 6.65 & 81.21 & 107.87 & 28 & 86.20 & 5.2 & 76.17 & 99.05 & 6.57 & 0.00 \\
\hline & GS & 32 & 91.81 & 5.89 & 82.31 & 104.34 & 28 & 84.51 & 4.99 & 75.77 & 96.19 & 7.30 & 0.001 \\
\hline \multirow{2}{*}{$\begin{array}{l}\text { Maximum ramus height, } \\
\text { right** }^{*}\end{array}$} & MS & 32 & 59.19 & 6.06 & 44.62 & 70.15 & 28 & 52. & 5.15 & 38.97 & 62.08 & 6.48 & 0.001 \\
\hline & GS & 32 & 59.28 & 5.97 & 36.38 & 70.55 & 28 & 53.73 & 5.51 & 41.87 & 68.00 & 5.56 & 0.001 \\
\hline \multirow{2}{*}{$\begin{array}{l}\text { Maximum ramus height, } \\
\text { left }(n=59)\end{array}$} & MS & 32 & 58.39 & 5.33 & 47.38 & 67.77 & 27 & 51.59 & 4.66 & 44.18 & 61.37 & 6.79 & 0.001 \\
\hline & GS & 32 & 59.64 & 5.52 & 47.12 & 71.60 & 27 & 52.61 & 5.17 & 42.95 & 63.59 & 7.03 & 0.001 \\
\hline \multirow{2}{*}{$\begin{array}{l}\text { Mandibular length } \\
\text { (projection) }(n=59)\end{array}$} & MS & 32 & 71.09 & 5.71 & 61.23 & 81.74 & 28 & 69.18 & 4.06 & 59.99 & 77.48 & .91 & 0.146 \\
\hline & GS & 32 & 73.07 & 4.87 & 64.79 & 86.31 & 28 & 70.60 & 3.86 & 62.28 & 79.57 & 2.46 & 0.036 \\
\hline \multirow{2}{*}{ Bicondylar breadth } & MIS & 32 & 110.10 & 6.35 & 102.49 & 131.20 & 21 & 111.13 & 4.90 & 99.65 & 119.50 & .60 & 0.001 \\
\hline & GS & 32 & 2 & 6.97 & 98.29 & 131 & 27 & 1 & 6 & 89.36 & 119.28 & 5.93 & 0.001 \\
\hline \multirow{2}{*}{ Bicoronoid breadth } & MS & 32 & 95.63 & 6.53 & 78.85 & 113.02 & 28 & 91.34 & 4.92 & 80.45 & 99.41 & 4.28 & 0.006 \\
\hline & GS & 32 & 95.94 & 6.58 & 78.58 & 113.23 & 28 & 90.79 & 5.7 & 73.89 & 99.33 & 5.15 & 0.002 \\
\hline \multirow{2}{*}{$\begin{array}{l}\text { Mandibular notch breadth, } \\
\text { right }(\mathrm{n}=59)\end{array}$} & MS & 32 & 3 & 350 & 25.22 & 3 & 28 & 30 & 2.86 & 23 & 38 & 77 & 0.003 \\
\hline & GS & 32 & 32.97 & 3.29 & 24.93 & 38.42 & 28 & 31.31 & 3.17 & 23.05 & 38.58 & 1.66 & 0.050 \\
\hline \multirow{2}{*}{$\begin{array}{l}\text { Mandibular notch breadth, } \\
\text { left }(n=59)\end{array}$} & MS & 32 & 33.47 & 3.46 & 25.89 & 39.33 & 27 & 30.98 & 2.64 & 26.36 & 37.64 & 2.49 & 0.003 \\
\hline & GS & 32 & 33.91 & 2.97 & 27.33 & 38.65 & 27 & 31.29 & 2.62 & 25.64 & 38.41 & 2.63 & 0.001 \\
\hline \multirow{2}{*}{$\begin{array}{l}\text { Height of the mandibular } \\
\text { body at the mental } \\
\text { foramen, right }\end{array}$} & MS & 32 & 25.39 & 5.18 & 12.76 & 35.60 & 28 & 21.25 & 5.21 & 9.26 & 30.41 & 4.14 & 0.001 \\
\hline & GS & 32 & 2 & 3.30 & 1 & & 28 & & 4 & & & 5 & 01 \\
\hline \multirow{2}{*}{$\begin{array}{l}\text { Height of the mandibular } \\
\text { body at the mental } \\
\text { foramen, left }\end{array}$} & MS & 32 & 20.13 & 0.10 & 8.59 & 35.83 & 28 & 21.30 & 5.12 & 9.66 & 30.65 & 4.37 & 0.001 \\
\hline & GS & 32 & 26.39 & 6.17 & 9.09 & 35. & 28 & 21.24 & 5.98 & 8.5 & 31. & 5.14 & 0.001 \\
\hline \multirow{2}{*}{ Bimental breadth } & TVIU & 32 & 40.04 & 0.21 & (3). & 50.91 & 28 & 40.00 & 2.40 & 38.85 & 49.80 & 1.81 & 0.024 \\
\hline & GS & 32 & 46.47 & 3.72 & 34.83 & 51.72 & 28 & 44.58 & 2.46 & 39.33 & 50.28 & 1.89 & 0.001 \\
\hline \multirow{2}{*}{$\begin{array}{l}\text { Breadth of the mandibular } \\
\text { body, right }\end{array}$} & MS & 32 & 10.65 & 2.31 & 0.11 & 10.58 & 28 & 7.00 & 1.44 & 0.90 & 10.47 & 0.77 & 0.135 \\
\hline & GS & 32 & 15.97 & 5.05 & 7.0 & 2 & 28 & 14 & 4.2 & 9. & 7 & 1.83 & 0.001 \\
\hline \multirow{2}{*}{$\begin{array}{l}\text { Breadth of the mandibular } \\
\text { body, left }\end{array}$} & MS & 32 & 10.30 & 2.57 & 4.94 & 17.47 & 28 & 9.84 & 1.70 & 6.4 & 14.29 & 0.45 & 0.432 \\
\hline & GS & 32 & 10.90 & 4.01 & 8.49 & 24.74 & 28 & 13.01 & 4.03 & 9.2 & 24. & 2.10 & 0.067 \\
\hline \multirow{2}{*}{$\begin{array}{l}\text { Minimum ramus breadth } \\
(\mathrm{n}=59)\end{array}$} & $\Lambda$ & 31 & ? & 406 & ? & 30 & 0 & 20 & 2 & 53 & 31 & 2 & 0.079 \\
\hline & GS & 31 & 30.85 & 4.13 & 23.80 & 40.13 & 28 & 29.23 & 2.72 & 24.10 & 35.04 & 1.62 & 0.083 \\
\hline & MS & 32 & 121.20 & 1.01 & 110.00 & 131.00 & 20 & 0 & 1.10 & 111.00 & 138.00 & -2.30 & 0.215 \\
\hline & GS & 32 & 127.55 & 8.26 & 113.45 & 145.60 & 28 & 130 & 6.92 & 116.86 & 142.29 & -3.06 & 0.128 \\
\hline & MS & 32 & 122.22 & 7.73 & 111.00 & 137.00 & 28 & 124.27 & 7.43 & 112.00 & 138.00 & -2.05 & 0.301 \\
\hline & GS & 32 & 128.54 & 8.64 & 111.58 & 146.76 & 28 & 131.12 & 7.09 & 116.25 & 141.43 & -2.58 & 0.215 \\
\hline & MS & 32 & 13.82 & 1.80 & 9.80 & 17.19 & 27 & 12.41 & 1.93 & 8.56 & 16.02 & 1.41 & 0.005 \\
\hline & GS & 32 & 13.69 & 1.78 & 9.99 & 16.90 & 27 & 12.33 & 1.98 & 8.95 & 16.61 & 1.36 & 0.006 \\
\hline & MS & 31 & 13.77 & 1.91 & 9.74 & 16.59 & 25 & 12.50 & 2.24 & 0.20 & 16.00 & 1.28 & 0.025 \\
\hline & GS & 31 & 13.78 & 1.96 & 9.61 & 16.73 & 25 & 12.52 & 2.18 & 8.48 & 16.32 & 1.25 & 0.027 \\
\hline
\end{tabular}

MS: mandible stabilizer; GS: gold standard. 
Table 5. ROC curve of the measurements using the mandible stabilizer (MS) and the tomographic measurements (GS, golden standard) for each sex.

\begin{tabular}{|c|c|c|c|c|}
\hline \multirow{2}{*}{ Variable } & \multicolumn{4}{|c|}{ ROC curve for each sex $(n=60)$} \\
\hline & Cat. & Area under the ROC curve $(p)$ & Associated criterion & Sensibility-specificity \\
\hline \multirow{2}{*}{ Maximum mandibular length } & MS & $0.739(0.001)$ & $>101.68$ & $78.12-64.29$ \\
\hline & GS & $0.686(0,008)$ & $>105.19$ & $71.97-64.29$ \\
\hline \multirow{2}{*}{ Bigonial width } & MS & $0.778(0.001)$ & $>89.95$ & $65.62-82.14$ \\
\hline & GS & $0.823(0.001)$ & $>90.43$ & $62.50-89.29$ \\
\hline \multirow{2}{*}{ Maximum ramus height, right** } & MS & $0.794(0.001)$ & $>55.70$ & $75.00-78.57$ \\
\hline & GS & $0.797(0.001)$ & $>54.79$ & $93.75-60.71$ \\
\hline \multirow{2}{*}{ Maximum ramus height, left $(n=59)$} & MS & $0.882(0.001)$ & $>56.54$ & $75.00-85.19$ \\
\hline & GS & $0.819(0.001)$ & $>57.84$ & $75.00-85.19$ \\
\hline \multirow{2}{*}{ Mandibular length (projection) $(n=59)$} & MS & $0.593(0.210)$ & $>72.89$ & $40.63-85.71$ \\
\hline & GS & $0.643(0.048)$ & $>72.33$ & $56.25-75.00$ \\
\hline \multirow{2}{*}{ Bicondylar breadth } & MS & $0.758(0.001)$ & $>113.58$ & $78.12-66.67$ \\
\hline & GS & $0.760(0.001)$ & $>114.81$ & $65.62-81.48$ \\
\hline \multirow{2}{*}{ Bicoronoid breadth } & MS & $0.708(0.001)$ & $>96.98$ & $43.75-96.43$ \\
\hline & GS & $0.747(0.001$ & $>97.21$ & $46.88-96.43$ \\
\hline \multirow{2}{*}{ Mandibular notch breadth, right $(n=59)$} & MS & $0.650(0.037$ & $>31.47$ & $68.75-60.71$ \\
\hline & GS & $0.646(0.043)$ & $>33.37$ & $46.88-85.71$ \\
\hline \multirow{2}{*}{ Mandibular notch breadth, left $(n=59)$} & MS & $0.729(0.001)$ & $>30.41$ & $84.37-59.26$ \\
\hline & GS & $0.738(0.001)$ & $>32.62$ & $62.50-85.19$ \\
\hline \multirow{2}{*}{$\begin{array}{l}\text { Height of the mandibular body at the } \\
\text { mental foramen, right }\end{array}$} & MS & $0.710(0.002)$ & $>25.09$ & $56.25-82.19$ \\
\hline & GS & $0.732(0,001)$ & $>25.06$ & $62.50-78.57$ \\
\hline \multirow{2}{*}{$\begin{array}{l}\text { Height of the mandibular body at the } \\
\text { mental foramen, left }\end{array}$} & MS & $0.730(0.001)$ & $>22.52$ & $75.00-64.29$ \\
\hline & GS & $0.732(0.001)$ & $>24.20$ & $71.87-67.86$ \\
\hline \multirow{2}{*}{ Bimental breadth } & MS & $0.670(0.001)$ & $>44.74$ & $62.50-78.57$ \\
\hline & GS & $0.689(0.001)$ & $>46.04$ & $62.50-82.14$ \\
\hline \multirow{2}{*}{ Breadth of the mandibular body, right } & MS & $0.592(0.209)$ & $>11.41$ & $31.25-92.86$ \\
\hline & GS & $0.608(0.147)$ & $>16.25$ & $50.00-78.57$ \\
\hline \multirow{2}{*}{ Breadth of the mandibular body, left } & MS & $0.531(0.680)$ & $>12.23$ & $21.87-96.43$ \\
\hline & GS & $0.638(0.063)$ & $>14.65$ & $56.25-78.57$ \\
\hline \multirow{2}{*}{ Minimum ramus breadth $(\mathrm{n}=59)$} & MS & $0.618(0.117)$ & $>31.04$ & $41.94-89.29$ \\
\hline & GS & $0.615(0.126)$ & $>31.69$ & $48.39-85.71$ \\
\hline \multirow{2}{*}{ Mandibular angle, right } & MS & $0.599(0.178)$ & $>122.00$ & $65.62-53.57$ \\
\hline & GS & $0.599(0.182)$ & $>122.90$ & $28.12-92.86$ \\
\hline \multirow{2}{*}{ Mandibular angle, left } & MS & $0.573(0.331)$ & $>117.00$ & $31.25-85.71$ \\
\hline & GS & $0.587(0.243)$ & $>126.42$ & $43.75-75.00$ \\
\hline \multirow{2}{*}{ Mandibular notch depth, right $(\mathrm{n}=59)$} & MS & $0.707(0.002)$ & $>13.11$ & $71.87-66.67$ \\
\hline & GS & $0.0 .707(0.023)$ & $>13.11$ & $71.87-66.67$ \\
\hline \multirow{2}{*}{ Mandibular notch depth, left $(n=56)$} & MS & $0.665(0.024)$ & $>13.75$ & $61.29-68.00$ \\
\hline & GS & $0.667(0.023)$ & $>13.37$ & $64.52-68.00$ \\
\hline
\end{tabular}


that the mandibular angle measurement has been mainly used for age estimation. ${ }^{18}$

Multivariate analysis considering several skull and mandible characteristics at the same time achieves better results than individual measurements. ${ }^{5}$ With more cranial and mandibular traits analyzed, better results are achieved. Walker ${ }^{5}$ found that five cranial traits evaluated together classified $90 \%$ of the individuals correctly.

It is necessary to perform studies in several populations to discriminate sex because temporal and spatial variations can contribute to differences among different population groups. ${ }^{5}$ The MS should be used in several populations, including ancient and modern, so that more precise sexual dimorphism parameters can be established. There are variations within and among populations because hormonal and environmental factors can affect bone growth. ${ }^{19}$

An investigation performed using skulls and mandibles in South Africa showed that several mandibular characteristics were useful in studying the sexual dimorphism, and the measure that was most dimorphic was bigonial breadth. ${ }^{4}$

The limitations of the study include focusing on a specific sample of the metropolitan area of São Paulo, Brazil from the Institute of Teaching and Research in Forensic Sciences of Guarulhos. It is important to take into consideration that a documented sample does not mean that it is representative of an entire population group ${ }^{20}$ as most worldwide collections are used for convenience. Therefore, more studies are necessary in other population groups using the same methods to establish parameters for adequate measurements to elucidate sexual dimorphism in modern and archaeological collections. ${ }^{20}$

Another aspect that should be discussed is that the Brazilian population is mixed, so there is a low probability of selecting mandibles from exclusively white, brown or black persons. In addition, when the genomic ancestry of Brazilian individuals was evaluated, low differences were observed among the regions of the country. ${ }^{21}$

\section{Conclusion}

The mandible stabilizer achieved the aim of discriminating sexual dimorphism using mandible measurements. Some measures exhibit an increased potential to differentiate sex compared with other measures.

\section{Acknowledgments}

This investigation was fund by the State of São Paulo's Research Fund (FAPESP, processes numbers 2012/19111-4 and 2014/13340-7).

\section{References}

1. Schmittbuhl M, Le Minor JM, Schaaf A, Mangin P. The human mandible in lateral view: elliptical fourier of the outline and their morphological analysis. Ann Anat. 2002;184(2):199-207. doi: 10.1016/S0940-9602(02)80021-8

2. Kranioti EF, Işcan MY, Michalodimitrakis M. Craniometric analysis of the modern Cretan population. Forensic Sci Int. 2008;180(2-3):110.e1-5. doi:10.1016/j.forsciint.2008.06.018

3. Williams BA, Rogers T. Evaluating the accuracy and precision of cranial morphological traits for sex determination. J Forensic Sci. 2006;51(4):729-35. doi:10.1111/j.1556-4029.2006.00177.x

4. Steyn M, Işcan MY. Sexual dimorphism in the crania and mandibles of South African whites. Forensic Sci Int. 1998; 98(1-2):9-16. doi:10.1016/S0379-0738(98)00120-0

5. Walker PL. Sexing skulls using discriminant function analysis of visually assessed traits. Am J Phys Anthropol. 2008;136(1):39-50. doi:10.1002/ajpa.20776
6. Schmittbuhl M, Rieger J, Le Minor JM, Schaaf A, Guy F. Variations of the mandibular shape in extant hominoids: generic, specific, and subspecific quantification using elliptical fourier analysis in lateral view. Am J Phys Anthropol. 2007;132(1):119-31. doi:10.1002/ajpa.20476

7. De Villiers H. The skull of the South African Negro. Johannesburg: Witwatersrand University Press, 1968.

8. Rogers T, Saunders S. Accuracy of sex determination using morphological traits of the human pelvis. J Forensic Sci. 1994;39(4):1047-56. doi:10.1520/JFS13683J

9. Loth SR, Henneberg M. Mandibular ramus flexure: a new morphologic indicator of sexual dimorphism in the human skeleton. Am J Phys Anthropol. 1996;99(3):473-85. doi:10.1002/ (SICI)1096-8644(199603)99:3<473::AID-AJPA8>3.0.CO;2-X

10. Patriquin ML, Loth SR, Steyn M. Sexually dimorphic pelvic morphology in South African whites and blacks. Homo. 2003;53(3):255-62. doi:10.1078/0018-442X-00049 
11. Recommendations for age and sex diagnoses of skeletons. J Hum Evolut. 1980;9(7):517-49. doi:10.1016/00472484(80)90061-5

12. Haun SJ. Brief communication: a study of the predictive accuracy of mandibular ramus flexure as a singular morphologic indicator of sex in an archaeological sample. Am J Phys Anthropol. 2000 Mar;111(3):429-32. doi:10.1002/(SICI)1096-8644(200003)111:3<429:: AID-AJPA9>3.0.CO;2-1

13. Squarcia SM, Sidorkewicj NS, Camina R, Casanave EB. Sexual dimorphism in the mandible of the armadillo Chaetophractus villosus (Desmarest, 1804) (Dasypodidae) from northern Patagonia, Argentina. Braz J Biol. 2009;69(2):347-52. doi:10.1590/S1519-69842009000200016

14. Azevedo AC, Alves NZ, Michel-Crosato E, Rocha M, Cameriere R, Biazevic MG. Dental age estimation in a Brazilian adult population using Cameriere's method. Braz Oral Res. 2015;29(1):1-9. doi:10.1590/1807-3107BOR-2015.vol29.0016

15. Carvalho SP, Brito LM, Paiva LA, Bicudo LA, Crosato EM, Oliveira RN. Validation of a physical anthropology methodology using mandibles for gender estimation in a Brazilian population. J Appl Oral Sci. 2013;21(4):358-62. doi:10.1590/1678-775720130022
16. Lin C, Jiao B, Liu S, Guan F, Chung NE, Han SH et al. Sex determination from the mandibular ramus flexure of Koreans by discrimination function analysis using three-dimensional mandible models. Forensic Sci Int. 2014;236:191.e1-6. doi:10.1016/j.forsciint.2013.12.015

17. Giles E. Sex determination by discriminant function analysis of the mandible. Am J Phys Anthropol. 1964;22(2):129-35. doi:10.1002/ajpa.1330220212

18. Vodanovic M, Dumancic J, Demo Z, Mihelic D. Determination of sex by discriminant function analysis of mandibles from two Croatian archaeological sites. Acta Stomatol Croat. 2006;40(3):263-77.

19. Balci Y, Yavuz MF, Cağdir S. Predictive accuracy of sexing the mandible by ramus flexure. Homo. 2005;55(3):229-37. doi:10.1016/j.jchb.2004.07.006

20. Komar DA, Grivas C. Manufactured populations: what do contemporary reference skeletal collections represent? A comparative study using the Maxwell Museum documented collection. Am J Phys Anthropol. 2008;137(2):224-33. doi:10.1002/ajpa.20858

21. Pena SD, Di Pietro G, Fuchshuber-Moraes M, Genro JP, Hutz MH, Kehdy Fde S, et al. The genomic ancestry of individuals from different geographical regions of Brazil is more uniform than expected. PLoS One. 2011;6(2):e17063. doi:10.1371/journal.pone.0017063 